\title{
Experimental 3-D Vector Velocity Estimation with Row-Column Addressed Arrays
}

\author{
Holbek, Simon; Stuart, Matthias Bo; Jensen, Jørgen Arendt
}

Published in:

Proceedings of IEEE International Ultrasonics Symposium

Link to article, DOI:

10.1109/ULTSYM.2016.7728399

Publication date:

2016

Document Version

Peer reviewed version

Link back to DTU Orbit

Citation (APA):

Holbek, S., Stuart, M. B., \& Jensen, J. A. (2016). Experimental 3-D Vector Velocity Estimation with Row-Column Addressed Arrays. In Proceedings of IEEE International Ultrasonics Symposium IEEE.

https://doi.org/10.1109/ULTSYM.2016.7728399

\section{General rights}

Copyright and moral rights for the publications made accessible in the public portal are retained by the authors and/or other copyright owners and it is a condition of accessing publications that users recognise and abide by the legal requirements associated with these rights.

- Users may download and print one copy of any publication from the public portal for the purpose of private study or research.

- You may not further distribute the material or use it for any profit-making activity or commercial gain

- You may freely distribute the URL identifying the publication in the public portal 


\title{
Experimental 3-D Vector Velocity Estimation with Row-Column Addressed Arrays
}

\author{
Simon Holbek, Matthias Bo Stuart, and Jørgen Arendt Jensen \\ Center for Fast Ultrasound Imaging, Dept. of Elec. Eng., Bldg. 349, Technical University of Denmark, \\ 2800 Kgs. Lyngby, Denmark
}

\begin{abstract}
Experimental 3-D vector flow estimates obtained with a 62+62 2-D row-column (RC) array with integrated apodization are presented. A transverse oscillation (TO) velocity estimator is implemented on a 3.0 MHz RC array, to yield realtime 3-D vector flow in a cross-sectional scan plane at 750 frames per second. The method is validated in a straight-vessel phantom $(\varnothing=8 \mathrm{~mm})$ connected to a flow pump capable of generating timevarying carotid waveforms. The out-of-plane velocity component perpendicular to the cross section of the vessel and the crosssectional area is used to estimate volumetric flow rates. The flow rate measured from five cycles is $2.3 \mathrm{~mL} /$ stroke $\pm 0.1 \mathrm{~mL} / \mathrm{stroke}$ giving a negative $9.7 \%$ bias compared to the pump settings. It is concluded that 124 elements are sufficient to estimate 3-D vector flow, if they are positioned in a row-column wise manner.
\end{abstract}

\section{INTRODUCTION}

Row-column (RC) addressed 2-D arrays have been suggested as an alternative to the fully populated matrix array for volumetric imaging at a low channel cost [1], [2]. Compared to a $N \times N$ matrix array, the total number of interconnections in a $N+N \mathrm{RC}$ array is reduced by a factor of $N / 2$, which eases the interconnect and opens up for transducers with both a large footprint and a small pitch. For instance, a $62+62$ array uses 124 connections instead of 3844 for the matrix array.

Established and fully tested methods implemented on conventional fully populated matrix arrays, are not directly transferable to RC arrays. For instance, the tall elements produce several ghost echoes emanating from the element edges, which degrades the image quality [2], [3]. A suggested solution to reduce the ghost echoes without affecting the main echo, was to implement a hardware roll-off apodization at the end of each element [3]. Furthermore, the approximation of the elements being small point-sources breaks down, due to the dimensions of the tall elements. A better approximation is therefore to view the elements as line segments, which influences the timeof-flight calculations used in the delay-and-sum beamformer [3].

All these precautions were implemented in previous work, which in a simulation study showed that $3-\mathrm{D}$ vector flow could be estimated in a plane by using a $62+623.0 \mathrm{MHz} 2-\mathrm{D}$ $\mathrm{RC}$ array in combination with a dedicated 3-D RC transverse oscillation (TO) method [4]. Preliminary experimental results with a similar capacitive micromachined ultrasonic transducer (CMUT) demonstrated that 3-D vector flow in an M-mode setup could be obtained for a constant laminar flow [5].

This paper presents a selection of the work presented in the journal article [6] using a piezo RC prototype prope. It is here demonstrated, that similar results can be obtained in an experimental setup, where 3-D vector flow is estimated in a plane in a pulsatile environment.

\section{MATERIALS \& METHOD}

\section{A. Experimental setup}

A $62+62$ 3.0 MHz 2-D piezo RC prototype probe, made in collaboration with Sound Technology, Inc. (State College, PA, USA) [7], was used in the experiments with properties as described in Table I. Each end of the elements contained an integrated hardware roll-off apodization. The RC array was connected to the experimental ultrasound scanner SARUS [8], which stored raw RF from all 124 channels at a sampling frequency of $35 \mathrm{MHz}$ and at an excitation voltage of $75 \mathrm{~V}$.

\section{B. Flow pump}

Measurements were conducted in a customized tissue mimicking phantom (Dansk Fantom Service, Frederiksund, Denmark) containing a straight-vessel $(\varnothing=8 \mathrm{~mm})$, which was surrounded by a tissue mimicking material. A flow system (CompuFlow 1000, Shelley Medical Imaging Technologies, Toronto, Canada) was connected to the straight-vessel phantom. The flow pump was able to generate a pre-defined timevarying carotid flow waveform with a manufacturer specified flow rate accuracy of $\pm 3 \%$.

\section{Focusing with RC arrays}

The wavefront from a single RC element can be viewed as a plane wave in one plane and a circle arc in the orthogonal plane. Therefore, when multiple line elements are excited according to a specified delay curve, the wavefronts will add up to form a focal line rather than a focal point. Steered focused emissions along a focal line were therefore achieved through electronically specified delay curves in the transmit stage.

If the same elements are used for both transmitting and receiving, the beamformed data will correspond to the averaged received echo along the focal line, since focused emissions generate a line shaped pressure field. Due to this, receive beamforming was made with elements oriented orthogonally to the emitting elements. 


\section{Beamforming}

A dedicated RC delay-and-sum beamformer [3] was used, which takes the position of the emitting element (source), the time of emission, and the position of the receiving elements (drains) as input for calculating the shortest time-of-flight between the transmit element, the beamformed point, and the receiving element.

\section{E. Emission sequence}

A steered transmit sequence was used to estimate 3-D vector flow in the cross-sectional plane in a vessel as shown in Fig. 1. The sequence consisted of one focused emission $C_{1}$ using column elements and $N$ focused emissions $R_{i}$ using row elements, where $i=1 \ldots N$. For $N=1$, the emission sequence is denoted an M-mode sequence. 3-D vector flow was, thus, estimated in points along the $N$ steered directions in the $z y$-plane. The column emission generated a plane wave within the cross sectional $z y$-scan plane, whereas plane waves perpendicular to the scan plane were steered in the $z y$-plane when using the row elements. From the row transmit event $R_{i}$, the $v_{x_{i}}$ and $v_{z_{i}}$ velocity components could be estimated in points along the direction of the respective beamformed centerline. However, the $C_{1}$ column transmit event provided the required data for beamforming the lines needed for estimating all $v_{y_{i}}$ and $v_{z_{i}}$ velocity components, as this transmit event insonifies the $z y$-scan plane. The steered transmit sequence used is schematically written as

$$
\begin{aligned}
& C_{1} \rightarrow R_{1} \rightarrow R_{2} \rightarrow R_{3} \rightarrow \ldots R_{N} \\
& C_{1} \rightarrow R_{1} \rightarrow R_{2} \rightarrow R_{3} \rightarrow \ldots R_{N}
\end{aligned}
$$

This sequence provided continuous data, which means that the distance between each identical emission type is equally distributed in time for all time [9]. The advantages of continuous data are, that very high frames rate can be obtained, and that dynamic ensemble lengths and echo canceling filters can be applied. The higher obtainable frame rate with continuous data occurs, since a sliding window can be applied on the beamformed data to generate one velocity estimate. The velocity estimate can be updated from each new similar emissions, since the new data can replace the oldest data in the estimator.

\section{F. The transverse oscillation method}

With the transverse oscillation (TO) method [10], [11], it is possible to estimate two velocity components, if a 1-D array is used; one component perpendicular to the element orientation in addition to the axial component. Three beamformed lines are needed for this; one center line for the axial estimator and two steered lines for the transverse estimate. The center line $r_{c e n t e r}$ is beamformed along the direction $(0,0, z)$, using delay-and-sum and a traditional apodization profile. For the two steered lines, a traditional TO apodization profile with two separated peaks is applied and beamforming is performed
TABLE I

Transducer AND EMISSIONS SEQUENCE SETUP

\begin{tabular}{ll}
\hline & Transducer \\
Parameter & Value \\
\hline Trandsucer type & 2-D Row-Column \\
No. of elements in $x$ and $y$ & 62 \\
Pitch in $x$ and $y$ & $0.27 \mathrm{~mm}$ \\
Width & $0.245 \mathrm{~mm}$ \\
Kerf & $0.025 \mathrm{~mm}$ \\
Sampling frequency & $35 \mathrm{MHz}$ \\
Center frequency & $3.0 \mathrm{MHz}$ \\
Footprint size & $1.67 \times 1.67 \mathrm{~cm}^{2}$ \\
\hline
\end{tabular}

along the lines $(x, y, z)=\left( \pm \lambda_{x}(z) / 8,0, z\right)$ to create the $\lambda_{x} / 4$ spatial separation. With a 2-D matrix array, all 5 lines required for 3-D TO can be beamformed from one transmit event [12], [13]

If an interleaved transmit/receive sequence contains both events with transmit on rows and receiving with column elements and vice verca, all three velocity components can be estimated with a 2-D RC array.

\section{DATA PROCESSING}

The raw RF data were processed on a Linux cluster. Matched filtering was applied on the individual channel data by convolving with the time-reversed emitted pulse to increase SNR. From each transmit event three lines were beamformed. Two of the lines, $r_{\text {left }}$ and $r_{\text {right }}$, were used to estimate the velocity component perpendicular to the tallest dimension of the receiving elements using the TO method, and the third line, $r_{\text {center }}$, was used to estimate the axial velocity with an autocorrelation approach [14]. Echo cancellation of the beamformed data were subsequently performed with a low frequency Doppler filter algorithm [15]. After echo cancelling, the data were fed to the respective velocity estimators. By combining the estimated transverse velocity components, one from each transmit event, with one of the two independent axial estimates, a 3-D velocity vector along the direction of the respective beamformed centerline was obtained. An estimation plane was obtained by scan converting and interpolating the estimates.

\section{EXPERIMENTAL SETUP}

With the described material two measurements were performed with an M-mode and a steered emission sequence. Both measurements used an ensemble length of 32 emissions per velocity estimate. The M-mode had a pulse repetition frequency $f_{p r f}$ of $750 \mathrm{~Hz}$. The steered sequence consisted of 11 row emissions spanning from $-8^{\circ}$ to $8^{\circ}$ in steps of $1.6^{\circ}$ and a single unsteered column emission, from which 3 -D vector flow was obtained in a cross-sectional scan plane. $f_{p r f}$ was $9.0 \mathrm{kHz}$, which translates to 750 frames per second.

\section{Results}

Results from the M-mode measurements are shown in Fig. 2 , where the time-varying velocity component in the flow direction is illustrated. The results shows the pulsating flow 


\section{Steered Sequence}
Transmit
TO beamforming on columns on rows

\section{$2-\mathrm{D}$ velocity estimates}
vector flow
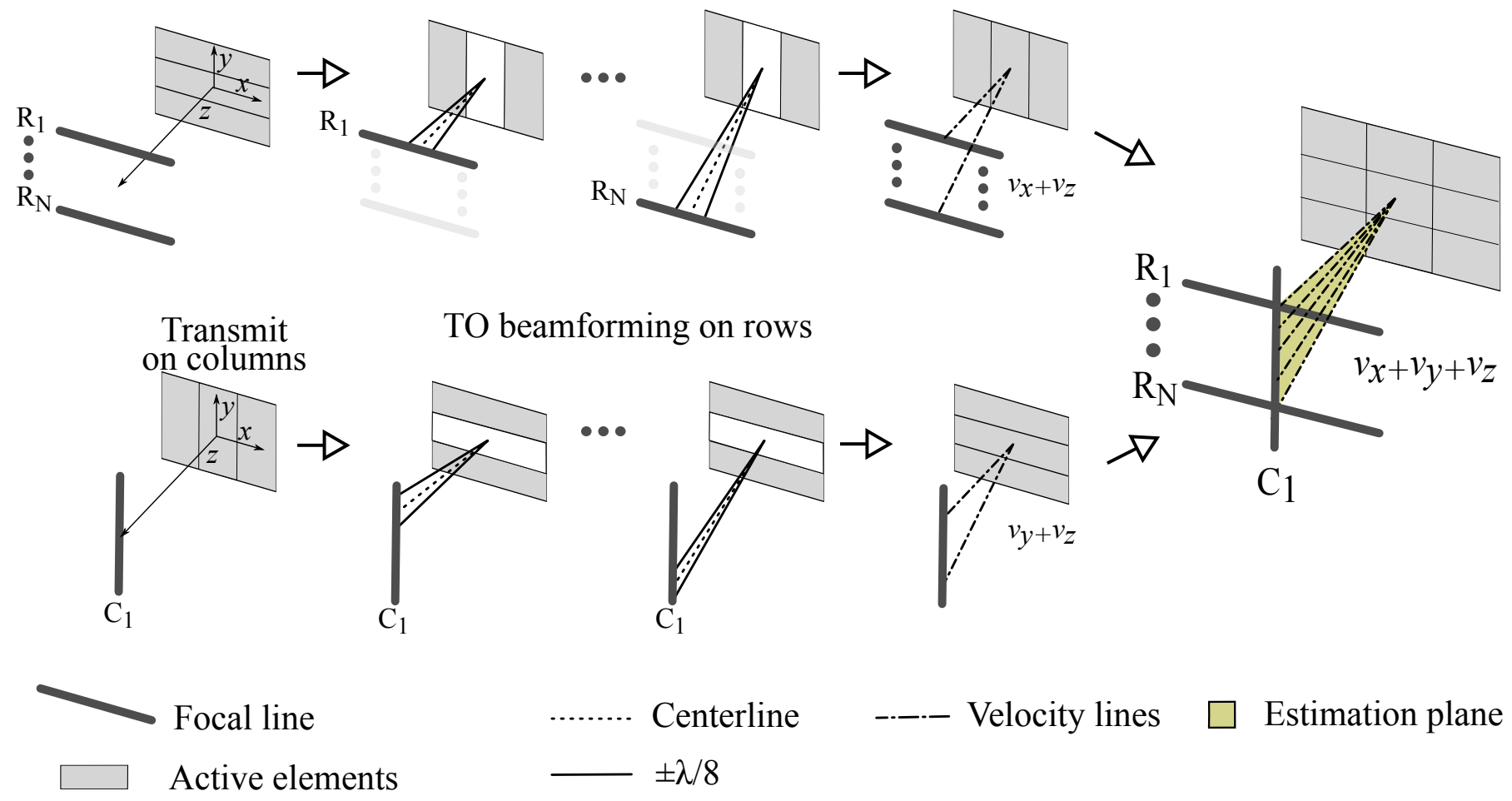

Fig. 1. RC steered sequence for 3-D vector flow obtained in a cross sectional plane with TO is designed in the following way; first, after each column emission $C_{1}$, multiple steered row emissions $R_{N}$ are emitted. From each row emission three lines are beamformed according to the steering directions and $v_{x}$ and $v_{z}$ can be estimated along each direction. Second, from a single column emission $C_{1}$, three lines are beamformed along each steering direction yielding $v_{y}$ and $v_{z}$ velocity estimates along the $N$ directions. 3-D vector flow is estimated in points along directions originating from the center of the aperture and through the intersection between the focal lines. The estimation plane is obtained when interpolating the combined 3-D vector flow estimates.

pattern, and the estimated mean velocity at the vessel center during one period was $11.3 \mathrm{~cm} / \mathrm{s} \pm 0.4 \mathrm{~cm} / \mathrm{s}$, when averaging over 10 periods.

For the steered sequence, a total of $4.3 \mathrm{~s}$ were recorded, corresponding to 5 cycles. Based on the manufacturer specified cycle time, the estimates were divided into 5 sub samples, and were subsequently coherently aligned. The flow rate, based on the cross sectional vessel area and the out-of-plane velocity component averaged over 5 cycles was $2.3 \mathrm{~mL} /$ stroke $\pm 0.1 \mathrm{~mL} /$ stroke, compared to the expected $2.54 \mathrm{~mL} / \mathrm{stroke}$, corresponding to a negative bias of $9.7 \%$. Due to the continuous data acquisition a high frame rate with a high temporal resolution can be achieved. The high frame rate captures the repeating pulsating behavior and the higher velocities during peak-systole were $25.6 \mathrm{~cm} / \mathrm{s} \pm 0.9 \mathrm{~cm} / \mathrm{s}$ and the lowest velocities during end-diastole were $1.1 \mathrm{~cm} / \mathrm{s} \pm 0.7 \mathrm{~cm} / \mathrm{s}$. A 3 -D vector representation of the flow both during the peaksystole and end-diastole is seen in Fig. 3.

\section{CONCLUSION}

The performance of the presented method, showed that in a pulsatile setup, both the slow and fast flow could be estimated,

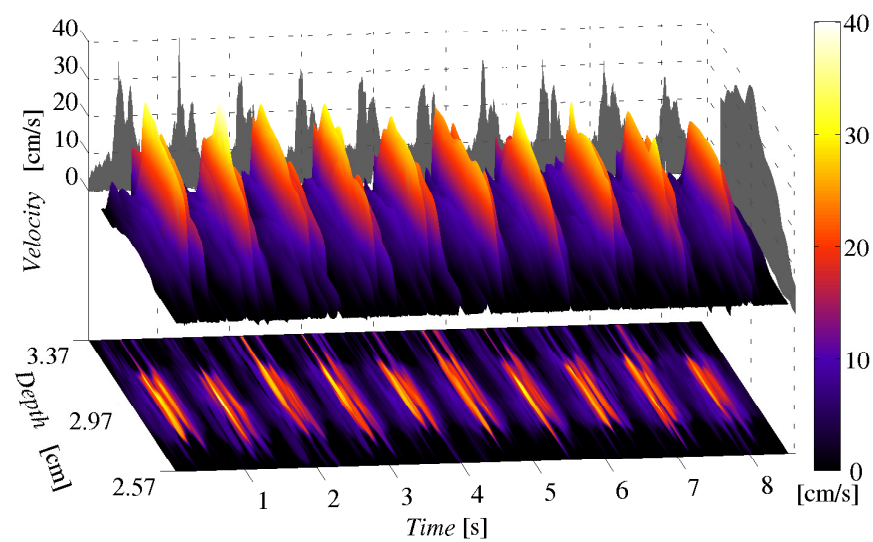

Fig. 2. M-mode of the velocity component in the flow direction measured in a pulsating carotid flow setup.

and that the estimated flow rates from 5 cycles gave a negative bias of $9.7 \%$. The standard deviation on the flow rates was less than 5\%, which shows that the estimates are consistent and 

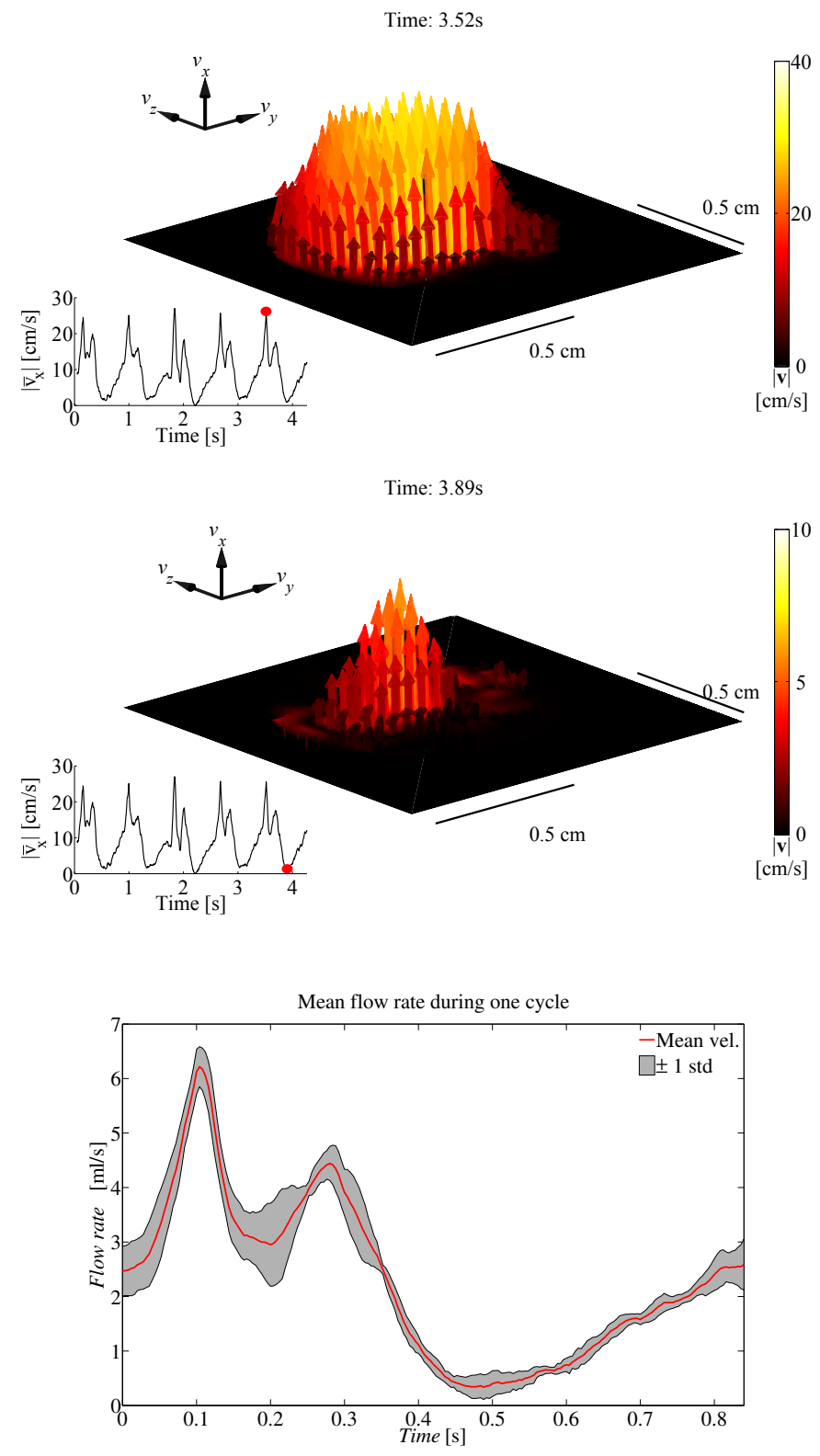

Fig. 3. Cross sectional 3-D vector flow representation estimated in the pulsating setup during (a) peak-systole and (b) end-diastole. Please note that the velocity scale during peak-systole is four times larger than for the enddiastole. c) mean flow rate with on standard deviation averaged across 5 cycles.

reproducible. The negative bias is expected to be due to the degree of beam-steering, which changes the double oscillating TO field and requires further optimization.

However, the presented results demonstrate that a setup with only 124 elements is sufficient to estimate $3-\mathrm{D}$ vector flow. This channel count is similar to that of conventional probes, making realtime implementation on standard commercial plat- forms possible.

\section{ACKNOWLEDGMENT}

This work was supported by grant 82-2012-4 from the Danish National Advanced Technology Foundation and by BK Ultrasound Aps.

\section{REFERENCES}

[1] C. E. Morton and G. R. Lockwood, "Theoretical assessment of a crossed electrode 2-D array for 3-D imaging," in Proc. IEEE Ultrason. Symp., 2003, pp. 968-971.

[2] C. E. M. Démoré, A. Joyce, K. Wall, and G. Lockwood, "Real-time volume imaging using a crossed electrode array," IEEE Trans. Ultrason., Ferroelec., Freq. Contr., vol. 56, no. 6, pp. 1252-1261, 2009.

[3] M. F. Rasmussen, T. L. Christiansen, E. V. Thomsen, and J. A. Jensen, "3-D imaging using row-column-addressed arrays with integrated apodization - Part I: Apodization design and line element beamforming," IEEE Trans. Ultrason., Ferroelec., Freq. Contr., vol. 62, no. 5, pp. 947-958, 2015.

[4] S. Holbek, T. L. Christiansen, M. F. Rasmussen, M. B. Stuart, E. V. Thomsen, and J. A. Jensen, "3-D vector velocity estimation with rowcolumn addressed arrays," in Proc. IEEE Ultrason. Symp., 2015, pp. $1-4$.

[5] S. Holbek, T. L. Christiansen, M. Engholm, A. Lei, M. B. Stuart, C. Beers, L. N. Moesner, J. P. Bagge, E. V. Thomsen, and J. A. Jensen, "3-D vector flow using a row-column addressed CMUT array," in Proc. SPIE Med. Imag., vol. 9790, 2016, pp. 979 005-979 005-8.

[6] S. Holbek, T. L. Christiansen, M. B. Stuart, C. Beers, E. V. Thomsen, and J. A. Jensen, "3-D vector flow estimation with row-column addressed arrays," IEEE Trans. Ultrason., Ferroelec., Freq. Contr., p. Accepted, 2016.

[7] M. Engholm, T. L. Christiansen, C. Beers, J. P. Bagge, L. N. Moesner, H. Bouzari, A. Lei, M. Berkheimer, M. B. Stuart, J. A. Jensen, and E. V. Thomsen, "A hand-held row-column addressed CMUT probe with integrated electronics for volumetric imaging," in Proc. IEEE Ultrason. Symp., 2015, pp. 1-4.

[8] J. A. Jensen, H. Holten-Lund, R. T. Nilsson, M. Hansen, U. D. Larsen, R. P. Domsten, B. G. Tomov, M. B. Stuart, S. I. Nikolov, M. J. Pihl, Y. Du, J. H. Rasmussen, and M. F. Rasmussen, "SARUS: A synthetic aperture real-time ultrasound system," IEEE Trans. Ultrason., Ferroelec., Freq. Contr., vol. 60, no. 9, pp. 1838-1852, 2013.

[9] S. I. Nikolov and J. A. Jensen, "In-vivo Synthetic Aperture Flow Imaging in Medical Ultrasound," IEEE Trans. Ultrason., Ferroelec., Freq. Contr., vol. 50, no. 7, pp. 848-856, 2003.

[10] J. A. Jensen and P. Munk, "A new method for estimation of velocity vectors," IEEE Trans. Ultrason., Ferroelec., Freq. Contr., vol. 45, pp. 837-851, 1998.

[11] J. A. Jensen, "A new estimator for vector velocity estimation," IEEE Trans. Ultrason., Ferroelec., Freq. Contr., vol. 48, no. 4, pp. 886-894, 2001.

[12] M. J. Pihl and J. A. Jensen, "A transverse oscillation approach for estimation of three-dimensional velocity vectors. Part I: Concept and simulation study," IEEE Trans. Ultrason., Ferroelec., Freq. Contr., vol. 61, pp. 1599-1607, 2014.

[13] M. J. Pihl, M. B. Stuart, B. G. Tomov, M. F. Rasmussen, and J. A. Jensen, "A transverse oscillation approach for estimation of threedimensional velocity vectors. Part II: Experimental validation," IEEE Trans. Ultrason., Ferroelec., Freq. Contr., vol. 51, no. 10, pp. 16081618, 2014.

[14] C. Kasai, K. Namekawa, A. Koyano, and R. Omoto, "Real-Time TwoDimensional Blood Flow Imaging using an Autocorrelation Technique," IEEE Trans. Son. Ultrason., vol. 32, pp. 458-463, 1985.

[15] A. P. G. Hoeks, J. J. W. van de Vorst, A. Dabekaussen, P. J. Brands, and R. S. Reneman, "An efficient algorithm to remove low frequency Doppler signal in digital Doppler systems," Ultrason. Imaging, vol. 13, pp. 135-145, 1991. 